Keywords: metastatic renal cell carcinoma; targeted molecular therapy; outcomes assessment; overall survival; progression-free survival; mTOR inhibitor; VEGF inhibitor; benchmarks; international metastatic renal cell cancer database consortium

\title{
First-, second-, third-line therapy for mRCC: benchmarks for trial design from the IMDC
}

\author{
J J Ko ${ }^{1}$, T K Choueiri ${ }^{2}$, B I Rini ${ }^{3}$, J-L Lee ${ }^{4}$, N Kroeger ${ }^{1,5}$, S Srinivas ${ }^{6}$, L C Harshman ${ }^{7}$, J J Knox ${ }^{8}$,
} G A Bjarnason9, M J MacKenzie ${ }^{10}, \mathrm{~L} \mathrm{Wood}^{11}, \mathrm{U}$ N Vaishampayan ${ }^{12}, \mathrm{~N} \mathrm{Agarwal}^{13}, \mathrm{~S} \mathrm{~K} \mathrm{Pal}^{14}$, M-H Tan ${ }^{15}$, S Y Rha ${ }^{16}$, T Yuasa $^{17}$, F Donskov ${ }^{18}$, A Bamias ${ }^{19}$ and D Y C Heng ${ }^{\star, 1}$

${ }^{1}$ Tom Baker Cancer Center, University of Calgary, Calgary, Alberta, Canada; ${ }^{2}$ Dana Farber Cancer Institute, Boston, Massachusetts, USA; ${ }^{3}$ Cleveland Clinic Taussig Cancer Institute, Cleveland, Ohio, USA; ${ }^{4}$ Department of Oncology, Asan Medical Center, University of Ulsan College of Medicine, Seoul, South Korea; ${ }^{5}$ Department of Urology, Universitätsmedizin Greifswald, Greifswald, Germany; ${ }^{6}$ Division of Oncology, Stanford Medical Center, Stanford, California, USA; ${ }^{7}$ Division of Oncology, Stanford Cancer Institute, Stanford School of Medicine, Stanford, California, USA; ${ }^{8}$ Department of Medicine, Princess Margaret Cancer Centre, University Health Network, University of Toronto, Toronto, Ontario, Canada; ${ }^{9}$ Sunnybrook Odette Cancer Centre, University of Toronto, Toronto, Ontario, Canada; ${ }^{10}$ London Health Sciences Center, London, Ontario, Canada; ${ }^{11}$ Queen Elizabeth II Health Sciences Centre and Dalhousie University, Halifax, Nova Scotia, Canada; ${ }^{12}$ Karmanos Cancer Institute, Wayne State University, Detroit, Michigan, USA; ${ }^{13}$ Huntsman Cancer Institute, University of Utah, Salt Lake City, Utah, USA; ${ }^{14}$ City of Hope Comprehensive Cancer Center, Medical Oncology \& Experimental Therapeutics, Duarte, California, USA; ${ }^{15}$ National Cancer Center, Institute of Bioengineering and Nanotechnology, Singapore, Singapore; ${ }^{16}$ Yonsei University Hospital, Seoul, South Korea; ${ }^{17}$ Department of Urology, Cancer Institute Hospital of Japanese Foundation for Cancer Research, Tokyo, Japan; ${ }^{18}$ Department of Oncology, Aarhus University Hospital, Aarhus, Denmark and ${ }^{19}$ Alexandra Peripheral General Hospital, Athens, Greece

Background: Limited data exist on outcomes for metastatic renal cell carcinoma (mRCC) patients treated with multiple lines of therapy. Benchmarks for survival are required for patient counselling and clinical trial design.

Methods: Outcomes of mRCC patients from the International mRCC Database Consortium database treated with 1, 2, or 3+ lines of targeted therapy (TT) were compared by proportional hazards regression. Overall survival (OS) and progression-free survival (PFS) were calculated using different population inclusion criteria.

Results: In total, 2705 patients were treated with TT of which 57\% received only first-line TT, $27 \%$ received two lines of TT, and 16\% received $3+$ lines of TT. Overall survival of patients who received 1,2, or $3+$ lines of TT were 14.9, 21.0, and 39.2 months, respectively, from first-line $T T(P<0.0001)$. On multivariable analysis, 2 lines and $3+$ lines of therapy were each associated with better OS (HR=0.738 and 0.626, $P<0.0001)$. Survival outcomes for the subgroups were as follows: for all patients, OS 20.9 months and PFS 7.2 months; for those similar to eligible patients in the first-line ADAPT trial, OS 14.7 months and PFS 5.6 months; for those similar to patients in first-line TIVO-1 trial, OS 24.8 months and PFS 8.2 months; for those similar to patients in second-line INTORSECT trial, OS 13.0 months and PFS 3.9 months; and for those similar to patients in the third-line GOLD trial, OS 18.0 months and PFS 4.4 months.

Conclusions: Patients who are able to receive more lines of TT live longer. Survival benchmarks provide context and perspective when interpreting and designing clinical trials.

*Correspondence: Dr DYC Heng; E-mail: daniel.heng@albertahealthservices.ca

Received 15 October 2013; revised 20 December 2013; accepted 8 January 2014; published online 1 April 2014

(c) 2014 Cancer Research UK. All rights reserved 0007-0920/14 
The advent of targeted therapy (TT) has dramatically changed the treatment paradigm and prognosis of metastatic renal cell carcinoma (mRCC). Seven agents are now approved or available for use in North America and Europe, and more are awaiting phase III results (Figlin et al, 2012; ClinicalTrials.gov Identifier: NCT01030783, NCT00664326, NCT01865747, NCT01136733, NCT00303862, NCT01472081, NCT01582672). In the last 10 years, the standard of care for a patient with mRCC has undergone multiple revisions, mainly due to the rapidity of emerging data from prospective trials. There is a growing need for benchmark survival data from real-life patients exposed to one or more of the contemporary targeted therapies. Such data can provide guidance for future prospective trials and set expectations for outcomes that new therapies should exceed.

A number of retrospective studies have examined different aspects of clinical experience with targeted therapies. The most studied agents are anti-vascular endothelial growth factor (VEGF) inhibitors, sunitinib and sorafenib, usually in the setting of sequential therapy or following immunotherapy (Buchler et al, 2012; Harrison et al, 2013; Wahlgren et al, 2013). Retrospective studies have been completed to investigate the optimal sequence of TKIs and other second-line therapies such as mammalian target of rapamycin (mTOR) inhibitors, as well as the timing of cytoreductive nephrectomy (Buchler et al, 2012; Giuliani and Drudi, 2012; Stenner et al, 2012; Stroup et al, 2013). A multicentre Swedish study has previously found that in 2753 patients treated from 2002 to 2008, the median overall survival (OS) was 9.6 months from 2002 to 2006, vs 12.4 months from 2006 to 2008 (Wahlgren et al, 2013). Given that the first targeted agent, sunitinib, was approved in 2006, the clinical experience with TT in this database had not matured, with a limited number of exposures to multiple lines of contemporary agents. Another large cohort study found the median OS of 18.8 months among those who were treated with first-line VEGF-targeted treatment, although the outcomes were reported in the context of prognostic model validation (Heng et al, 2013).

The objectives of the study were two-fold: first, to compare the survival outcomes of mRCC patients in the International mRCC Database Consortium (IMDC) cohort who were treated with first, second, third, or more lines of TT; second, to benchmark survival outcomes based on the different inclusion criteria for selected phase III trials of novel targeted agents. Our study evaluated the largest multicentre retrospective database of patients who have mRCC and have received one or more VEGF inhibitors or mTOR inhibitors over a 9-year period. We also examined OS and progression-free survival (PFS) of patients using inclusion criteria simulated from large phase III trials, both published and recently reported studies.

\section{MATERIALS AND METHODS}

Twenty international cancer centres in Canada, the United States, Japan, South Korea, Singapore, and Denmark provided data on consecutive patients with mRCC. All patients were treated with anti-VEGF TT for mRCC (sunitinib, sorafenib, bevacizumab, pazopanib, and axitinib) and/or mTOR inhibitors (temsirolimus and everolimus) between January 2004 and December 2012, either per standard of care or as part of clinical trials. Patients were allowed to have undergone previous immunotherapy, but only targeted therapies were counted as lines of therapy used in each patient. Patient lists were obtained in a consecutive fashion from pharmacy or registry data in each centre, which included every mRCC patient who received TT. Using uniform data templates, we collected baseline patient characteristics and survival data from medical chart reviews and publically available records. All centres obtained local institutional ethics approval before including data in the cohort.
We assessed the survival outcomes of patients who received only one line of TT, who received two lines of targeted therapies, and who received three or more targeted therapies. We then extracted data and analysed survival outcomes for the following six subgroups based on recent large prospective trials of TT:

- All patients who received at least one TT;

- Patients who received first-line TT with an intermediate or poor risk disease and whose diagnosis to treatment interval was less than 1 year, similar to those enrolled in Phase 3 Trial of Autologous Dendritic Cell Immunotherapy (AGS-003) Plus Standard Treatment of Advanced Renal Cell Carcinoma (ADAPT; ClinicalTrials.gov Identifier: NCT01582672);

- Patients who received first-line TT and previously underwent nephrectomy, similar to those enrolled in A Study to Compare Tivozanib (AV-951) to Sorafenib in Subjects With Advanced Renal Cell Carcinoma (TIVO-1; ClinicalTrials.gov Identifier: NCT01030783);

- Patients who received second-line TT after at least one other VEGF- TT, similar to those enrolled in Temsirolimus Vs Sorafenib As Second-Line Therapy In Patients With Advanced RCC Who Have Failed First-Line Sunitinib (INTORSECT; ClinicalTrials.gov Identifier: NCT00474786);

- All patients who received third-line therapy;

- Patients who received third-line TT and were previously exposed to one VEGF inhibitor and one mTOR inhibitor, similar to those enrolled in Study of Dovitinib Vs Sorafenib in Patients With Metastatic Renal Cell Carcinoma (GOLD; ClinicalTrials.gov Identifier: NCT01223027).

For each subgroup, we obtained the median OS and PFS, calculated from the line of therapy under consideration unless otherwise specified. We defined OS as the period between TT initiation and date of death, unless it was censored on the day of the last follow-up visit. We defined PFS as the period between treatment initiation and progression, drug cessation, or death, unless it was censored at the last follow-up visit. Progression was assessed radiologically using the Response Evaluation Criteria in Solid Tumors (RECIST), or clinically when continuation of treatment was deemed futile (Eisenhauer et al, 2009).

Statistical analysis. Baseline patient and disease characteristics were summarised using descriptive analysis. Overall survival and PFS were estimated for each sub-cohort with a $95 \%$ confidence interval (CI), and differences among the sub-cohorts were adjusted by the known independent predictors of poorer OS (KPS $<80 \%$, diagnosis to treatment interval $<1$ year, hypercalcemia, anemia, thrombocytosis, neutrophilia) using proportional hazards regression (Heng et al, 2009). The statistical analyses were performed using SAS version 9 (SAS Institute, Cary, NC, USA), and $P<0.05$ (two-sided) was considered statistically significant.

\section{RESULTS}

Patient and treatment characteristics. In total, 2705 patients were included in the study cohort with a median follow-up period of 37 months. Their baseline patient characteristics and therapies are summarised in Table 1. One thousand five hundred and thirty three patients $(57 \%)$ received or are still receiving 1 TT. The most frequently used first-line therapy was sunitinib, used in 1959 patients $(72 \%)$. This was followed by sorafenib in 474 patients (18\%) and bevacizumab in 109 patients (4\%). Other first-line choices included temsirolimus, pazopanib, everolimus, and axitinib. In total, 734 patients $(27 \%)$ received a total of two lines of 


\begin{tabular}{|c|c|}
\hline Characteristic & Median or proportion $\%$ \\
\hline Age (years) & 61 (IQR 54-68) \\
\hline Karnofsky performance status (\%) & 80 (IQR 80-90) \\
\hline Non-clear cell carcinoma, $n=2532$ & 309 (12\%) \\
\hline Sarcomatoid histology, $n=2312$ & $231(10 \%)$ \\
\hline \multicolumn{2}{|c|}{ IMDC Prognostic Score, $\mathbf{n}=\mathbf{2 2 5 8}$} \\
\hline $\begin{array}{l}\text { Favourable } \\
\text { Intermediate } \\
\text { Poor }\end{array}$ & $\begin{array}{r}431(19 \%) \\
1243(55 \%) \\
584(26 \%)\end{array}$ \\
\hline \multicolumn{2}{|l|}{ First-line therapy, $n=2703$} \\
\hline $\begin{array}{l}\text { Sunitinib } \\
\text { Sorafenib } \\
\text { Bevacizumab } \\
\text { Temsirolimus } \\
\text { Pazopanib } \\
\text { Everolimus } \\
\text { Axitinib } \\
\text { Other }\end{array}$ & $\begin{array}{c}1959(72 \%) \\
474(18 \%) \\
109(4 \%) \\
66(2 \%) \\
62(2 \%) \\
22(1 \%) \\
4(<1 \%) \\
7(<1 \%)\end{array}$ \\
\hline \multicolumn{2}{|l|}{ Second-line therapy, $n=1175$} \\
\hline $\begin{array}{l}\text { Sorafenib } \\
\text { Sunitinib } \\
\text { Everolimus } \\
\text { Temsirolimus } \\
\text { Pazopanib } \\
\text { Bevacizumab } \\
\text { Immunotherapy } \\
\text { Axitinib } \\
\text { Cabozantinib }\end{array}$ & $\begin{array}{c}328(28 \%) \\
280(24 \%) \\
269(23 \%) \\
152(13 \%) \\
49(4 \%) \\
45(4 \%) \\
24(2 \%) \\
20(2 \%) \\
8(<1 \%)\end{array}$ \\
\hline \multicolumn{2}{|l|}{ Third-line therapy, $n=460$} \\
\hline $\begin{array}{l}\text { Everolimus } \\
\text { Sunitinib } \\
\text { Temsirolimus } \\
\text { Sorafenib } \\
\text { Pazopanib } \\
\text { Bevacizumab } \\
\text { Clinical Trial } \\
\text { Immunotherapy } \\
\text { Axitinib }\end{array}$ & $\begin{array}{l}99(23 \%) \\
79(17 \%) \\
77(17 \%) \\
76(17 \%) \\
41(9 \%) \\
33(7 \%) \\
27(6 \%) \\
17(3 \%) \\
11(2 \%)\end{array}$ \\
\hline
\end{tabular}

therapy, whereas only 438 patients (16\%) received three or more lines of therapy.

Survival outcomes in the IMDC cohort. The median OS in patients who received only one TT was 14.9 months from the time of first-line therapy initiation (95\% CI, 13.2-16.7 months), with PFS of 6.7 months (95\% CI, 5.9-7.5 months). In contrast, the median OS in patients who received two lines of therapy was 21.0 months, measured from the time of first-line therapy initiation (95\% CI, 19.1-23.5 months), with PFS of 3.4 months, measured from the time of second-line therapy initiation (95\% CI, 3.0-3.9 months). Patients who received three or more lines of TT had an OS of 39.2 months, measured from the time of first-line initiation (95\% CI, 36.3-41.9 months), with PFS of 4 months, measured from the time of third-line therapy initiation (95\% CI, 3.4-4.5 months). On multivariable analysis, adjusting for the IMDC prognostic criteria, receiving second-line or third-line therapy was independently associated with better OS (HR $=0.738,95 \%$ CI $0.663-0.821$; $\mathrm{HR}=0.626$, 95\% CI 0.541-0.724, respectively, both $P<0.0001$ ).
Table 2 summarises the survival outcomes of the six subgroups, as described above.

\section{DISCUSSION}

Survival benchmark studies provide context when designing and interpreting new clinical trials. Outcomes from real-life cohorts treated with current standard therapies serve as comparators for future clinical trials, with the expectation that newer therapies will perform better than the standard therapies. The benchmarked outcomes can also allow for future statistical considerations such as sample size for new prospective trials. Prior benchmark studies in mRCC were limited to patients who received cytokine immunotherapy (Belldegrun et al, 2008). Since the initial Food and Drug Administration (FDA) approval of sorafenib in 2005, contemporary targeted therapies have now largely replaced immunotherapy as the new standard of care. This study is, to the authors' knowledge, the first and largest multi-national benchmarking study to date of mRCC patients treated with at least one line of TT.

One of the limitations in our methodology is its retrospective patient recruitment. Patients included in our cohort were not selected on a certain criteria or hand-picked by each centre; rather, they were derived from consecutive patient lists in pharmacy or registry data. This strategy was employed to minimise inherent selection bias, to reflect clinical practice as closely as possible, and to include all patients receiving TT as part of standard-of-care or clinical trials. The denominator for patients who received one line of TT is unknown and may vary across centres. However, the denominator for patients who received two lines of TT is, by definition, patients who received one line of TT, and the denominator for patients who received three lines of TT is patients who received two lines of TT; this allows us to assess and compare outcomes in sub-groups within our patient cohorts.

The study compares real-life retrospective survival outcomes with those reported in prospective trials. Since the era of immunotherapy, the median OS of patients in our study cohort, from the time of first-line agent use, has doubled (Belldegrun et al, 2008). The outcomes are slightly inferior to, but still comparable with, those reported in the updated sunitinib phase III study, in the pazopanib phase III study, or those reported in TIVO-1 (summarised in Table 3) (Motzer et al, 2009; Sternberg et al, 2013). This type of comparison is exploratory in nature. The small difference is likely due to the difference in patient inclusion criteria, with non-clear cell histology and patients with poor functional status, brain metastases, and comorbidities in the real-life cohort, who would have otherwise been excluded in clinical trials. The results in our study, therefore, not only confirm and support the findings in prospective trials, but are also generalisable to a wider, more heterogeneous range of patients and clinical practices across the centres.

In regards to the survival from the initiation of the second-line therapy, the outcomes for patients who received second-line TT in our cohort are comparable to the outcomes from the INTORSECT and RECORD-1 trials, and only slightly inferior to the AXIS trial (summarised in Table 3) (Motzer et al, 2008; Rini et al, 2011). The outcomes for patients in our study who have received a third-line TT after a TKI and an mTOR inhibitor, have exceeded the median survival outcome of GOLD trial, for both the study and control arms (summarised in Table 3). Trials for other novel therapies, including lenvatinib, regorafenib, cediranib, AGS-003, cabozantinib, and nivolumab, are ongoing or have preliminary results. The survival outcomes in our study will serve as benchmark for these studies.

In our study, sunitinib was the most popular first-line therapy, but the diversity of first-line and second-line therapy choices 
Table 2. OS and PFS in the specified sub-cohorts using data from the IMDC (see Materials and Methods)

\begin{tabular}{|c|c|c|c|c|}
\hline \multirow[b]{2}{*}{ Groups } & \multicolumn{2}{|c|}{ OS } & \multicolumn{2}{|c|}{ PFS } \\
\hline & $\begin{array}{l}\text { Number of } \\
\text { patients }\end{array}$ & $\begin{array}{l}\text { Months } \\
(95 \% \mathrm{Cl})\end{array}$ & $\begin{array}{l}\text { Number of } \\
\text { patients }\end{array}$ & $\begin{array}{l}\text { Months } \\
(95 \% \mathrm{Cl})\end{array}$ \\
\hline All patients receiving first-line TT & 2705 & $20.9(19.6-22.5)$ & 2659 & $7.2(6.7-7.7)$ \\
\hline $\begin{array}{l}\text { Patients receiving first-line TT with the following: } \\
\text { Intermediate or poor risk disease } \\
\text { Diagnosis to treatment interval }<1 \text { year }{ }^{\text {a }} \\
\text { Similar to inclusion criteria per ADAPT }\end{array}$ & 1189 & $14.7(13.3-16.5)$ & 1174 & $5.6(5.3-6.1)$ \\
\hline $\begin{array}{l}\text { Patients receiving first-line TT, with prior nephrectomy }{ }^{a} \\
\text { Similar to inclusion criteria per TIVO-1 }\end{array}$ & 2117 & $24.8(23.1-27.3)$ & 2080 & $8.2(7.8-8.6)$ \\
\hline $\begin{array}{l}\text { Patients receiving second-line TT after at least one other } \mathrm{TT}^{\mathrm{b}} \\
\text { Similar to inclusion criteria per INTORSECT }\end{array}$ & 1157 & $13.0(12.2-14.7)$ & 1151 & $3.9(3.6-4.3)$ \\
\hline All patients receiving third-line therapy ${ }^{c}$ & 455 & $12.1(10.7-13.9)$ & 425 & $4.0(3.4-4.5)$ \\
\hline $\begin{array}{l}\text { Patients receiving third-line therapy and previously exposed to at least one VEGF } \\
\text { inhibitor and one mTOR inhibitor } \\
\text { Similar to inclusion criteria per GOLD }\end{array}$ & 147 & $18.0(11.8-24.0)$ & 140 & $4.4(3.3-5.2)$ \\
\hline $\begin{array}{l}\text { Abbreviations: OS = overall survival; PFS = progression-free survival; } T T=\text { targeted therapy. } \\
\text { a OS and PFS calculated from the time of first-line therapy initiation. } \\
b_{O} O S \text { and PFS calculated from the time of second-line therapy initiation. } \\
{ }^{C} O S \text { and PFS calculated from the time of third-line therapy initiation. }\end{array}$ & & & & \\
\hline
\end{tabular}

Table 3. Survival outcomes from phase III studies of first-, second-, and third-line targeted therapies against an approved agent or placebo

\section{OS} PFS

\begin{tabular}{|c|c|c|}
\hline \multicolumn{3}{|l|}{ First-line } \\
\hline $\begin{array}{l}\text { Sunitinib phase III study } \\
\text { (sunitinib vs interferon alpha) }\end{array}$ & $\begin{array}{l}26.4 \text { vs } 21.8 \\
\text { months }(P=0.051)\end{array}$ & $\begin{array}{l}11 \text { vs } 5 \text { months } \\
(P<0.001)\end{array}$ \\
\hline $\begin{array}{l}\text { Pazopanib phase III study } \\
\text { (pazopanib vs placebo) }\end{array}$ & $\begin{array}{l}22.9 \text { vs } 20.5 \\
\text { months }(P=0.224)\end{array}$ & $\begin{array}{l}9.2 \text { vs } 4.2 \text { months } \\
(P<0.0001)\end{array}$ \\
\hline TIVO-1 (tivozanib vs sorafenib) & $\begin{array}{l}28.8 \text { vs } 29.3 \\
\text { months }(P=0.105)\end{array}$ & $\begin{array}{l}11.9 \text { vs } 9.1 \\
\text { months } \\
(P=0.042)\end{array}$ \\
\hline \multicolumn{3}{|l|}{ Second-line } \\
\hline $\begin{array}{l}\text { RECORD-1 (everolimus vs } \\
\text { placebo) }\end{array}$ & $\begin{array}{l}13.57 \text { vs } 13.01 \\
\text { months }(P=0.23)\end{array}$ & $\begin{array}{l}4.9 \text { vs } 1.87 \\
\text { months } \\
(P<0.0001)\end{array}$ \\
\hline $\begin{array}{l}\text { INTORSECT (temsirolimus vs } \\
\text { sorafenib) }\end{array}$ & $\begin{array}{l}16.64 \text { vs } 12.27 \\
\text { months }(P=0.01)\end{array}$ & $\begin{array}{l}4.28 \text { vs } 3.91 \\
\text { months }(P=0.19)\end{array}$ \\
\hline AXIS (axitinib vs sorafenib) & $\begin{array}{l}20.1 \text { vs } 19.2 \\
\text { months }(P=0.37)\end{array}$ & $\begin{array}{l}6.7 \text { vs } 4.7 \text { months } \\
(P<0.001)\end{array}$ \\
\hline \multicolumn{3}{|l|}{ Third-line } \\
\hline GOLD (dovitinib vs sorafenib) & $\begin{array}{l}11.1 \text { vs } 11.0 \\
\text { months }(P=0.357)\end{array}$ & $\begin{array}{l}3.7 \text { vs } 3.6 \text { months } \\
(P=0.063)\end{array}$ \\
\hline
\end{tabular}

indicates that the sequence of TT prescription may be practicedependent. In addition, until recently, data from head-to-head trial that tested the comparative effectiveness between front-line TKIs were limited. The recently published COMPARZ study shows that pazopanib was not inferior to sunitinib in terms of PFS as a firstline option in mRCC (Motzer et al, 2013). Thus, the survival advantage may be more associated with increasing lines of targeted therapies given, rather than their sequence, which corresponds with what was shown in prior studies (Motzer et al, 2008; Kirchner et al, 2010).

Reflecting the above observation, patients in our study who received more lines of therapy lived longer with longer PFS, adjusting for prognostic factors. This finding is comparable with results from randomised prospective second-line TT trials, which demonstrated an increased PFS with the use of TT compared with placebo (Motzer et al, 2008). Only 16\% of the patients in our study were exposed to three or more lines of TT. This is partly explained by the 9-year study period that encompasses evolving treatment paradigms. Some early years saw targeted therapies offered only as trial drugs, and less than three targeted therapies were approved or available in most participating centres until at least 2008. Our study included a diverse range of patients many of whom would have been excluded from clinical trials, and therefore may not have had the opportunity to receive more lines of therapy on a trial. On the other hand, the survival advantage likely also stems from the inherent selection bias in a retrospective cohort. Even with the currently approved regimens, many patients die or become too ill to receive more than one or two lines of therapy, especially if their diseases had unfavourable prognostic indicators.

\section{CONCLUSION}

The current management of mRCC involves an evolving algorithm with a goal to optimise the outcome for each individual patient with as many lines of TT as the patient may benefit from. We present long-term, multicentre data to provide an understanding of survival outcomes achievable with available therapeutic agents. We demonstrate a prolonged survival with one or more TT comparable with that of previous prospective trials. The results can serve as a benchmark to compare the outcomes of emerging treatment options and help shape the design of future trials with realistic expectations of outcomes such as PFS. 


\section{AUTHOR CONTRIBUTIONS}

DYCH and TKC were involved in the conception, study design, and statistical analysis of the article. JJK (first author) and DYCH were involved in writing of the article. DYCH, TKC, BIR, JLL, NK, SS, LCH, JJK (eighth author), GAB, MJK, LW, UNV, NA, SKP, MHT, SYR, TY, FD, AB, and DYCH provided and collected patient data. All authors approved the final article.

\section{REFERENCES}

A Phase II Uncontrolled Study of BAY73-4506 in Previously Untreated Patients With Metastatic or Unresectable RCC. In: ClinicalTrials.gov [Internet]. Bethesda (MD): National Library of Medicine (US). NLM Identifier: NCT00664326. Available from URL: http://www. clinicaltrials.gov/ct2/show/NCT00664326?term=regorafenib+renal+cell\& rank $=1$.

A Study of Cabozantinib (XL184) vs Everolimus in Subjects With Metastatic Renal Cell Carcinoma (METEOR). In: ClinicalTrials.gov [Internet]. Bethesda (MD): National Library of Medicine (US). NLM Identifier: NCT01865747. Available from URL: http://www.clinicaltrials.gov/ct2/ show/NCT01865747?term=cabozantinib+renal\&rank=1.

A Study of E7080 Alone, and in Combination With Everolimus in Subjects With Unresectable Advanced or Metastatic Renal Cell Carcinoma Following One Prior Vascular Endothelial Growth Factor (VEGF)Targeted Treatment. In: ClinicalTrials.gov [Internet]. Bethesda (MD): National Library of Medicine (US). NLM Identifier: NCT01136733. Available from URL: http://www.clinicaltrials.gov/ct2/show/ NCT01136733?term=NCT01136733\&rank=1.

A Study to Compare Tivozanib (AV-951) to Sorafenib in Subjects With Advanced Renal Cell Carcinoma (TIVO-1). In: ClinicalTrials.gov [Internet]. Bethesda (MD): National Library of Medicine (US). NLM Identifier: NCT01030783. Available from URL http://www.clinicaltrials. gov/ct2/show/NCT01030783?term=NCT01030783\&rank=1.

An Open-label, Randomized, Multi-center, Phase III Study to Compare the Safety and Efficacy of Dovitinib Versus Sorafenib in Patients With Metastatic Renal Cell Carcinoma After Failure of Anti-angiogenic (VEGF-targeted and mTOR Inhibitor) Therapies. ESMO (2013).

AZD2171 in Treating Patients With Refractory Metastatic Kidney Cancer. In: ClinicalTrials.gov [Internet]. Bethesda (MD): National Library of Medicine (US). NLM Identifier: NCT00303862. Available from URL: http://www.clinicaltrials.gov/ct2/show/NCT00303862?term= NCT00303862\&rank=1

Belldegrun AS, Klatte T, Shuch B, Larochelle JC, Miller DC, Said JW, Riggs SB, Zomorodian N, Kabbinavar FF, Dekernion JB, Pantuck AJ (2008) Cancerspecific survival outcomes among patients treated during the cytokine era of kidney cancer (1989-2005): a benchmark for emerging targeted cancer therapies. Cancer 113: 2457-2463.

Buchler T, Pavlik T, Bortlicek Z, Poprach A, Vyzula R, Abrahamova J, Melichar B (2012) Objective response and time to progression on sequential treatment with sunitinib and sorafenib in metastatic renal cell carcinoma. Med Oncol 29: 3321-3324.

Eisenhauer EA, Therasse P, Bogaerts J, Schwartz LH, Sargent D, Ford R, Dancey J, Arbuck S, Gwyther S, Mooney M, Rubinstein L, Shankar L, Dodd L, Kaplan R, Lacombe D, Verweij J (2009) New response evaluation criteria in solid tumours: revised RECIST guideline (version 1.1). Eur J Cancer 45: 228-247.

Figlin R, Sternberg C, Wood CG (2012) Novel agents and approaches for advanced renal cell carcinoma. J Urol 188: 707-715.

Giuliani J, Drudi F (2012) Immunotherapy and targeted therapies in metastatic renal cell carcinoma: is there a preferred sequence? Cancer Biother Radiopharm 27: 513-518.

Harrison MR, George DJ, Walker MS, Chen C, Korytowsky B, Kirkendall DT, Stepanski EJ, Abernethy AP (2013) "Real World" treatment of metastatic renal cell carcinoma in a joint communityacademic cohort: progression-free survival over three lines of therapy. Clin Genitourin Cancer 11(4): 441-450.
Heng DY, Xie W, Regan MM, Harshman LC, Bjarnason GA, Vaishampayan UN, Mackenzie M, Wood L, Donskov F, Tan MH, Rha SY, Agarwal N, Kollmannsberger C, Rini BI, Choueiri TK (2013) External validation and comparison with other models of the International Metastatic Renal-Cell Carcinoma Database Consortium prognostic model: a population-based study. Lancet Oncol 14: 141-148.

Heng DY, Xie W, Regan MM, Warren MA, Golshayan AR, Sahi C, Eigl BJ, Ruether JD, Cheng T, North S, Venner P, Knox JJ, Chi KN, Kollmannsberger C, Mcdermott DF, Oh WK, Atkins MB, Bukowski RM, Rini BI, Choueiri TK (2009) Prognostic factors for overall survival in patients with metastatic renal cell carcinoma treated with vascular endothelial growth factor-targeted agents: results from a large, multicenter study. J Clin Oncol 27: 5794-5799.

Kirchner H, Strumberg D, Bahl A, Overkamp F (2010) Patient-based strategy for systemic treatment of metastatic renal cell carcinoma. Expert Rev Anticancer Ther 10: 585-596.

Motzer RJ, Escudier B, Oudard S, Hutson TE, Porta C, Bracarda S, Grunwald V, Thompson JA, Figlin RA, Hollaender N, Urbanowitz G, Berg WJ, Kay A, Lebwohl D, Ravaud A, Group R-S (2008) Efficacy of everolimus in advanced renal cell carcinoma: a double-blind randomised, placebo-controlled phase III trial. Lancet 372: $449-456$.

Motzer RJ, Hutson TE, Cella D, Reeves J, Hawkins R, Guo J, Nathan P, Staehler M, De Souza P, Merchan JR, Boleti E, Fife K, Jin J, Jones R, Uemura H, De Giorgi U, Harmenberg U, Wang J, Sternberg CN, Deen K, Mccann L, Hackshaw MD, Crescenzo R, Pandite LN, Choueiri TK (2013) Pazopanib versus sunitinib in metastatic renal-cell carcinoma. $N$ Engl $J$ Med 369: 722-731.

Motzer RJ, Hutson TE, Tomczak P, Michaelson MD, Bukowski RM, Oudard S, Negrier S, Szczylik C, Pili R, Bjarnason GA, Garcia-Del-Muro X, Sosman JA, Solska E, Wilding G, Thompson JA, Kim ST, Chen I, Huang X, Figlin RA (2009) Overall survival and updated results for sunitinib compared with interferon alfa in patients with metastatic renal cell carcinoma. J Clin Oncol 27: 3584-3590

Nivolumab (BMS-936558; MDX-1106) in Combination With Sunitinib, Pazopanib, or Ipilimumab in Subjects With Metastatic Renal Cell Carcinoma (RCC) (CheckMate016). In: ClinicalTrials.gov [Internet]. Bethesda (MD): National Library of Medicine (US). NLM Identifier: NCT01472081. Available from URL: http://www.clinicaltrials.gov/ct2/ show/NCT01472081?term=nivolumab+renal\&rank=1.

Phase 3 Trial of Autologous Dendritic Cell Immunotherapy (AGS-003) Plus Standard Treatment of Advanced Renal Cell Carcinoma (RCC) (ADAPT). In: ClinicalTrials.gov [Internet]. Bethesda (MD): National Library of Medicine (US). NLM Identifier: NCT01582672. Available from URL http://clinicaltrials.gov/ct2/show/NCT01582672?term= NCT01582672\&rank=1\#wrapper.

Rini BI, Escudier B, Tomczak P, Kaprin A, Szczylik C, Hutson TE, Michaelson MD, Gorbunova VA, Gore ME, Rusakov IG, Negrier S, Ou YC, Castellano D, Lim HY, Uemura H, Tarazi J, Cella D, Chen C, Rosbrook B, Kim S, Motzer RJ (2011) Comparative effectiveness of axitinib versus sorafenib in advanced renal cell carcinoma (AXIS): a randomised phase 3 trial. Lancet 378: 1931-1939.

Stenner F, Chastonay R, Liewen H, Haile SR, Cathomas R, Rothermundt C, Siciliano RD, Stoll S, Knuth A, Buchler T, Porta C, Renner C, Samaras P (2012) A pooled analysis of sequential therapies with sorafenib and sunitinib in metastatic renal cell carcinoma. Oncology $\mathbf{8 2}$ 333-340.

Sternberg CN, Hawkins RE, Wagstaff J, Salman P, Mardiak J, Barrios CH, Zarba JJ, Gladkov OA, Lee E, Szczylik C, Mccann L, Rubin SD, Chen M, Davis ID (2013) A randomised, double-blind phase III study of pazopanib in patients with advanced and/or metastatic renal cell carcinoma: final overall survival results and safety update. Eur J Cancer 49: 1287-1296.

Stroup SP, Raheem OA, Palazzi KL, Liss MA, Mehrazin R, Kopp RP, Patel N, Cohen SA, Park SK, Patterson AL, Kane CJ, Millard F, Derweesh IH (2013) Does timing of cytoreductive nephrectomy impact patient survival with metastatic renal cell carcinoma in the tyrosine kinase inhibitor era? A multi-institutional study. Urology 81: $805-811$.

Study of Dovitinib Versus Sorafenib in Patients With Metastatic Renal Cell Carcinoma. In: ClinicalTrials.gov [Internet]. Bethesda (MD): National 
Library of Medicine (US). NLM Identifier: NCT01223027. Available from URL http://www.clinicaltrials.gov/ct2/show/NCT01223027?term= NCT01223027\&rank=1.

Temsirolimus Versus Sorafenib As Second-Line Therapy In Patients With Advanced RCC Who Have Failed First-Line Sunitinib (INTORSECT). In: ClinicalTrials.gov [Internet]. Bethesda (MD): National Library of Medicine (US). NLM Identifier: NCT00474786. Available from URL http://www.clinicaltrials.gov/ct2/show/NCT00474786?term= NCT00474786\&rank=1.
Wahlgren T, Harmenberg U, Sandstrom P, Lundstam S, Kowalski J, Jakobsson M, Sandin R, Ljungberg B (2013) Treatment and overall survival in renal cell carcinoma: a Swedish population-based study (2000-2008). Br J Cancer 108: 1541-1549.

This work is published under the standard license to publish agreement. After 12 months the work will become freely available and the license terms will switch to a Creative Commons AttributionNonCommercial-Share Alike 3.0 Unported License. 